\title{
Leaders of the two main parties in Britain since 1945
}

\begin{tabular}{|c|c|c|c|}
\hline Conservatives & $\begin{array}{l}\text { Period as } \\
\text { Conservative } \\
\text { leader }\end{array}$ & Labour & $\begin{array}{l}\text { Period as } \\
\text { Labour } \\
\text { leader }\end{array}$ \\
\hline Winston Churchill & $\begin{array}{l}1940-1955 \\
* 1940-1945 \\
1951-1955\end{array}$ & Clement Attlee & $\begin{array}{l}1935-1955 \\
* 1945-1951\end{array}$ \\
\hline Anthony Eden & $\begin{array}{l}1955-1957 \\
* 1955-1957\end{array}$ & Hugh Gaitskell & 1955-1963 \\
\hline Harold Macmillan & $\begin{array}{l}1957-1963 \\
* 1957-1963\end{array}$ & Harold Wilson & $\begin{array}{l}1963-1976 \\
* 1964- \\
1970 ; \\
1974-1976 \\
\end{array}$ \\
\hline $\begin{array}{l}\text { Alec Douglas } \\
\text { Home }\end{array}$ & $\begin{array}{l}1963-1965 \\
* 1963-1964\end{array}$ & $\begin{array}{l}\text { James } \\
\text { Callaghan }\end{array}$ & \begin{tabular}{|l|}
$1976-1981$ \\
$* 1976-1979$
\end{tabular} \\
\hline Edward Heath & $\begin{array}{l}1965-1975 \\
* 1970-1974\end{array}$ & Michael Foot & $1981-1983$ \\
\hline $\begin{array}{l}\text { Margaret } \\
\text { Thatcher }\end{array}$ & $\begin{array}{l}1975-1990 \\
* 1979-1990\end{array}$ & Neil Kinnock & 1983-1992 \\
\hline John Major & $\begin{array}{l}1990-1997 \\
* 1990-1997 \\
\end{array}$ & John Smith & 1992-1994 \\
\hline William Hague & $1997-2001$ & Tony Blair & $\begin{array}{l}1994-2007 \\
* 1997-2007\end{array}$ \\
\hline $\begin{array}{l}\text { Iain Duncan } \\
\text { Smith }\end{array}$ & $2001-2003$ & $\begin{array}{l}\text { Gordon } \\
\text { Brown }\end{array}$ & \begin{tabular}{|l|}
$2007-2010$ \\
$* 2007-2010$
\end{tabular} \\
\hline Michael Howard & 2003-2005 & Ed Miliband & $2010-$ \\
\hline David Cameron & $\begin{array}{l}2005- \\
* 2010-\end{array}$ & & \\
\hline
\end{tabular}

* denotes period in office as Prime Minister 